\title{
DISTINGUISHING COEFFICIENT DRIVEN SENSITIVITY ANALYSIS OF GRA MODEL FOR INTELLIGENT DECISIONS: APPLICATION IN PROJECT MANAGEMENT
}

\author{
Amin MAHMOUDI (D), Saad Ahmed JAVED (D)2,3*, \\ Sifeng LIU (D) ${ }^{4}$, Xiaopeng DENG (D) 5 \\ ${ }^{1,5}$ Department of Construction and Real Estate, School of Civil Engineering, \\ Southeast University, Nanjing 211189, P.R. China \\ ${ }^{2}$ School of Business, Nanjing University of Information Science and Technology, Nanjing, P.R. China \\ ${ }^{3}$ College of Economics and Management, Nanjing University of Aeronautics and Astronautics, \\ Nanjing, P.R. China \\ ${ }^{4}$ Institute for Grey Systems Studies, Nanjing University of Aeronautics and Astronautics, \\ Nanjing, P.R. China
}

Received 01 September 2019; accepted 20 October 2019

\begin{abstract}
The Distinguishing Coefficient $(\xi)$ is an important parameter of Grey Relational Analysis (GRA), a flagship multi-criteria decision making (MCDM) model of Grey System Theory, an intelligent and multifaceted field developed by Chinese scientists in 1980s. However, the scholars widely assume $\xi=0.5$. The current study questions this practice. Also, some scholars have argued that the variation in $\xi$ doesn't influence the ranking of the factors through GRA. On contrary, the study demonstrates, the variation in $\xi$ can influence the ranking. This has been shown through a case involving primary data concerning the perceived relative importance of Project Management Knowledge Areas (PMKAs). This study is significant for the analysts of uncertain systems, represented by grey or fuzzy systems, who intend to use GRA for intelligent multi-criteria decision making. It encourages $\xi$ - driven sensitivity analysis of GRA model before interpreting the results. The study reveals, by tailoring the value of $\xi$ a point can be achieved where the ranking obtained through GRA can be made most comparable to the other MCDM methods. For comparative analysis of the GRA based results the study deployed three other MCDM techniques; Analytic Hierarchy Process, Best Worst Method and Simple Additive Weighting.
\end{abstract}

Keywords: project management, knowledge areas, Grey Relational Analysis GRA, Simple Additive Weighing SAW, Analytic Hierarchy Process AHP, Best Worst Method BWM.

JEL Classification: C1, C8, L0, M0.

\footnotetext{
${ }^{*}$ Corresponding author. E-mail: saad.ahmed.javed@live.com
} 


\section{Introduction}

Projects are collective and purposeful endeavors driven by advancing collective comprehensions and interpretations of means and ends (Zavadskas et al., 2008). Project success (or failure) contribute to the success (or failure) of corporate strategies that's why projects are increasingly becoming an integral unit of corporations functioning in the competitive environments of today (Serra, 2017; Project Management Institute, 2013). With ever-increasing competition and uncertainties, more and more organizations are handling organizational issues on project management basis to achieve objectives at fast pace (Bakker, 2010; Winter et al., 2006). Nowadays, project management has seen its application in various kinds of organizations and sectors that encompasses both services and manufacturing industries (Kerzner, 2017, p. 2). In the past, project management was viewed as a threat to established lines of authority and thus to traditional way of managing organizational tasks, however today it is considered a competitive weapon to provide superior quality and services to the clients (Kerzner, 2014). Furthermore, knowledgeable and competent project managers are usually considered important to successes of projects (Hwang \& Ng, 2013; Project Management Institute, 2017) whose ability to balance the project constraints (time, cost, scope, quality, risk, etc.) in achieving project deliverables/objectives is well known in literature (Mahmoudi \& Feylizadeh, 2018). Thus, in a world where rates of project failures are too high to overlook (Serra, 2017) apprehending the mindset and priorities of these extremely important individuals becomes essential (Javed \& Liu, 2017).

Risks, uncertainties, complexities and unpredictability are important characteristics surrounding projects, project environments and project management processes (Floricel et al., 2016; Garel, 2013; He et al., 2015; Kaganer et al., 2013; Oun et al., 2016; Salet et al., 2013; Vanhoucke, 2013). These characteristics differentiate a temporary organizational system (project) from the permanent organizational systems (organizations) thus the application of an uncertainty theory like Grey System Theory in project management and related problems can be argued to be an apt attempt with vast scope of applications within project management field as the theory is well known for its ability to handle poorly understood uncertain systems (Javed \& Liu, 2017, 2019). If one closely observes the life cycle of a project, it can be easily observed that with the conclusion of each phase of project life cycle, new uncertain conditions and complexities arise that if not managed successfully can unfavourably influence project performance. Thus, a project is a grey system in its own right (Javed \& Liu, 2017), and existence of project risk management as one of the main areas of project management philosophy further strengthens this view. Therefore, the current study considers "project" a grey system because of uncertainties associated with projects and project management processes, and thus argues the application of Grey System Theory on the project/project management problems an appropriate initiative.

Project Management Institute (PMI) is an important organization of project management professionals in the United States and abroad. PMI classifies the project management knowledge into 10 interwoven areas (Project Management Institute, 2013). The all-inclusiveness of the number of the project management knowledge areas (PMKAs) can be debated yet their 
significance for the success of projects is well-known (Javed \& Liu, 2017). Several scholars have studied PMKAs in different industries and different perspectives/contexts. For instance, Crawford and Pollack (2007) studied nine PMKAs in their cross sectional study involving different countries, industries and application areas. Hwang and $\mathrm{Ng}$ (2013) summarized several PMKAs in their study involving green construction. Dumrak et al. (2017) investigated the relationship between PMKAs and sustainable outcomes in reproductive health development projects in Thailand. Oun et al. (2016) associated PMKAs to project success factors. Rocha et al. (2015) investigated PMKAs according to their relevance to project success in Portuguese construction sector. Nguyen et al. (2016) investigated PMKAs in academic/educational context. Eastham et al. (2014) ranked nine PMKAs in their study on PLM software selection model. Mesquida and Mas (2014) discussed ten PMKAs in their study on software development sector. Zwikael (2009) studied the relative importance of nine PMKAs during project planning. Review of past studies suggests that prioritization of PMKAs is an important area of research in project management research, and this information's usefulness for project managers to effectively utilize the available resources (Zwikael, 2009) further demonstrates the importance of this topic. However, why such an important topic is overlooked by the PM$\mathrm{BOK}^{\oplus}$ Guide further exposes the already evident weak theoretical foundation of the project management discipline (Garel, 2013; Padalkar \& Gopinath, 2016).

As it is difficult to get rid of uncertainties in most of our daily activities, the scholars have proposed various approaches to identify, control, and manage such uncertainties (Liao et al., 2015). Grey System Theory is one of the promising approaches to handle uncertainty in multi-attribute and multi-objective decision-making that has seen its application in various fields including project management (Javed, 2019). The distinguishing coefficient $(\xi)$ is an important parameter of Deng's GRA model however, its significance is usually overlooked by the scholars. Literature is full of studies where the value of $\xi$ is assumed to be 0.5 without justifying its deployment. In the words of Javed et al. (2018b), "usually, the scholars suppose the value of $\xi$ to be 0.5 even though the rationale behind this supposition is not yet universally established". Even the definition of Deng's GRA model states $\xi \in(0,1)$. Thus, arguing $\xi$ to be more of a dynamic parameter rather than a static parameter is established from its definition. Further, adding insult to the injury some scholars have argued that the variation in $\xi$ doesn't varies the final order of the factors/alternatives, prioritized through GRA model. For instance, Sallehuddin et al. (2008) claimed, "based on mathematic proof, the value change of $\xi$ will only change the magnitude of the relational coefficient, but it will not change the rank of the grey relational grade". They did not present any proof to justify this claim except one supporting reference, Jiang et al. (2002). Nevertheless, Jiang et al. (2002) simply stated, "It has been proved that the value will change the magnitude of the [grey] relational coefficients, while it will not change the ranking result". The proof is equally missing from their study. On the other hand, Song and Shepperd (2011) stated that the variation in $\xi$ will change the absolute value of grey relational coefficients (GRCs) without affecting their ranking order whereas slight variation in the ranking order of grey relational grades (GRGs) is equally possible. In the current study a comprehensive overview of the actual situation would be demonstrated through the real-world case while comparatively analyzing the results with 
that of three other MCDM methods; Analytic Hierarchy Process (AHP), Best Worst Method (BWM) and Simple Additive Weighting (SAW). While seconding Javed and Liu (2017), the current study considers "project" a grey system and aims to analyze the PMKAs in service and manufacturing sectors by recognizing the grey relations between the ten PMKAs and, then, ranking them, through the GRA and three other MCDM methods. Considering the fact that one the most pressing challenges nowadays is the selection and application of appropriate methods to guide researchers (Drouin et al., 2016) the current study deploys a set of traditional and emerging MCDM methods together to solve the problem. This makes the current study pioneer in its methodology to evaluate the ten PMKAs. Using these methods, the study strives to find out answers to the following questions.

- Which PMKA is perceived to be most and least significant for project success?

- How the results of GRA model differ when compared with that of other methods?

- How manufacturing and service industries' rankings differ and what insights do they shed on the difference of opinions among the project management professionals from the two industries?

- How the variations in $\xi$ influence these prioritizations?

- What insight can be drawn from the variation in the ranking order, if any?

- At what value of $\xi$, the ranks obtained through the GRA model are most comparable to other MCDM methods?

The study is organized as follows. After introduction, a brief outline of the literature has been presented to make the readers familiar with the important themes of the current study. This includes defining Project Management Knowledge Areas (PMKAs) and the four MCDM methods. In the third part, research methodology has been discussed. The fourth part presents results and discussion where GRA model has been executed on various values of $\xi$. Comparative analyses with other MCDM methods have also been presented. In the fifth and last part, the study has been concluded with some recommendations for both project management professionals and grey systems analysts.

\section{Overview of important themes}

\subsection{Grey Relational Analysis}

Decision making is the primary task of all humans and the output of our all daily activities depends on the soundness of our decisions however decision making is not always easy especially when the problem and associated information contain uncertainty, vagueness or complexity (Liao et al., 2017, 2018). When decision making involves uncertainty, the approaches like fuzzy logic and grey system theory becomes natural choice (Mahmoudi et al., 2019a; Liao \& Xu, 2017; Liu et al., 2017). Like fuzzy theory, grey system theory (GST) is a feasible mathematical approach for systems analysis described by imperfect information (Javed et al., 2019c). Grey Relational Analysis (GRA), also called Grey Correlation Analysis or Grey Incidence Analysis, is one of the core parts of Grey System Theory (Zhang et al., 2012). The theory has been recognized to be superior to comparable methodologies in the mathematical analysis of systems with uncertain information (Haeri \& Rezaei, 2019). GRA models are one of the new alternatives to the conventional statistical methods to analyze systems (Liu 
et al., 2017). The earliest GRA model was introduced by Professor Deng Julong in 1982 and it is still the most influential one (Liu et al., 2017; Li et al., 2011). The underline concept of GRA is to determine the extent of proximity between the data sequences by using the degree of similarity of geometric curves of the data sequences (Quartey-Papafio et al., 2019; Liu et al., 2017). GRA can be executed to expound a grey system whose physical prototype and operating mechanism are unclear (Zhang et al., 2012). GRA method has been adopted for probabilistic linguistic environment (Liang et al., 2018) and has been extended for predicting the experts' weights as well (Liang et al., 2019). Further, the deployment of the GRA model to handle MCDM problems is also well-established (Kuo et al., 2008). The foundation of the GRA model lies on Grey Relational Grade (GRG). If $X_{0}=\left(x_{0}(1), x_{0}(2), \ldots, x_{0}(n)\right)$ and $X_{i}=$ $\left(x_{i}(1), x_{i}(2), \ldots, x_{i}(n)\right)$ are two data sequences (reference sequence and alternative sequence, respectively) then the Deng's GRG is given by (Deng, 1989; Javed et al., 2018a)

$$
\gamma_{0 i}=\gamma\left(X_{0}, X_{i}\right)=\sum_{k=1}^{n} \gamma\left(x_{0}(k), x_{i}(k)\right) * w_{k},
$$

where $\gamma\left(x_{0}(k), x_{i}(k)\right)$ is the Grey Relational Coefficient (GRC) given by,

$$
\gamma\left(x_{0}(k), x_{i}(k)\right)=\frac{\min _{i} \min _{k}\left|x_{0}(k)-x_{i}(k)\right|+\xi \max _{i} \max _{k}\left|x_{0}(k)-x_{i}(k)\right|}{\left|x_{0}(k)-x_{i}(k)\right|+\xi \max _{i} \max _{k}\left|x_{0}(k)-x_{i}(k)\right|} .
$$

The weight $w_{\mathrm{k}}$ can be replaced by $1 / n$ when all factors are equally weighted. In the GRC formula, $\xi \in(0,1)$ is the distinguishing coefficient of the Deng's GRA model that adjusts the range of the comparative environment, and controls the relative differences among the grey relational coefficients associated with a problem (Wu et al., 2013). It can be varied depending on the uncertainty in the data (Javed, 2019). If the value of $\xi$ is smaller, the distinguishability between the data sequences is larger and if the value of $\xi$ is larger, the distinguishability is smaller (Abhang \& Hameedullah, 2012). The distinguishing coefficient is very interesting parameter of the model. Despite its ability to influence the grey relational ordering (the final ranking of the factors/alternatives), which will be confirmed in the succeeding sections of the current paper, the scholars usually presume its value to be 0.5 even though the logic behind this supposition is not recognized (Javed et al., 2018b) in spite of the fact that the effect of variation in $\xi$ on the variation in grey relational grade is well known (Wu \& Chen, 2005).

\subsection{Simple Additive Weighting method}

Simple Additive Weighting (SAW) approach is one of the most popular and simplest approaches of multi-criteria decision making. It has been reported that SAW was developed by MacCrimon (MacCrimmon, 1968), a consultant of RAND Corporation (Zavadskas et al., 2010). It is also called weighted sum method, weighted linear combination or scoring methods (Afshari et al., 2010; Chou et al., 2008). The SAW approach consists of two fundamental stages; first, scale/normalize the measures of all criteria (attributes) to make them comparable and then sum up the measures of all criteria for each alternative (Chou et al., 2008). The detailed steps to solve problems through SAW method can be found in Afshari et al. (2010). 


\subsection{Analytic Hierarchy Process}

The methodology of Analytic Hierarchy Process (AHP) was put forwarded by T. L. Saaty in 1970s (Saaty, 1986). AHP involves computing through pairwise comparisons and uses the experts' judgements to extract priority scales (Saaty, 2008). It is aimed for states in which qualitative information (intuitions, feelings, and sentiments) influencing the decision process are quantified to deliver a numeric scale for ranking the options (Taha, 2014). It is an important method to solve multi-attribute decision making problems and is being used since decades to appraise and support decisions having competing and multiple criteria by prioritizing all available decision alternatives (Ahn, 2017; Khalil et al., 2016; Shabbir \& Ahmad, 2016; Zahedi, 2008). AHP aids the decision makers in solving the complicated problem by disintegrating it into a multi-level hierarchic structure of objectives, attributes, sub-attributes and alternatives, and offers a scale of comparative degrees stated in dominance units to signify judgments in the form of pairwise comparisons (Xu \& Liao, 2014). An interesting discussion on AHP in light of previous studies can be found in Ahmed et al. (2017). Moreover, combination of AHP and other methods such as TOPSIS has been used in many research articles (Samanlioglu et al., 2018; Shaverdi et al., 2016). In short, since its release AHP is helping people in various fields and industries in making wise decisions when decision criterions are not few.

\subsection{Best/Worst Method}

Best/Worst Method (BWM) is one of the recent breakthroughs in the multiple criteria decision making discipline. BWM was developed by Jafar Rezaei in 2015. BWM was developed to overcome the drawbacks of AHP in terms of abundant pairwise comparisons and insufficient consistency (Mi et al., 2019; Mi \& Liao, 2019). In BWM, the most significant (best) and least significant (worst) attributes are pointed out by the decision makers followed by pairwise comparison between these criteria. Later by formulating a nonlinear maximin/minimax problem the weights of these criteria are determined. Details, properties and calculation steps of BWM can be found in Rezaei $(2015,2016)$ and Salimi and Rezaei (2018).

\subsection{Project Management Knowledge Areas}

Project management is one of the very crucial and vastly interdisciplinary shoots of management sciences (Mahmoudi et al., 2019b). Projects, the central theme of project management, imply temporary organizations (or, initiatives) that are usually unique, time-constrained and dependent on temporarily available people (Bourgault et al., 2008; Hietajärvi \& Aaltonen, 2018). Project Management Knowledge Areas (PMKAs) are the knowledge areas within project management philosophy, or the Project Management Body of Knowledge, identified by the $P M B O K^{\circledast}$ Guide, an authoritative publication by Project Management Institute, USA.

There are ten PMKAs so far identified by the Guide. This guide and the knowledge areas are guiding the project managers around the world since years. As per PMBOK (Project Management Institute, 2013), the PMKAs are: 
1. Project Integration Management (PIM);

2. Project Scope Management (PSM);

3. Project Time Management (PTM);

4. Project Cost Management (PCoM);

5. Project Quality Management (PQM);

6. Project Human Resource Management (PHRM);

7. Project Communications Management (PCmM);

8. Project Risk Management (PRM);

9. Project Procurement Management (PPM);

10. Project Stakeholder Management (PSHM).

For further details on each of the knowledge area the $P M B O K^{\circledast}$ Guide can be consulted.

\section{Research methodology}

For data collection, a workshop was organized in Lahore, the provincial capital of the most populous province of Pakistan. 104 project management related professionals were invited, but only thirty-three professionals arrived. They were from both manufacturing (PBOs) and services industries (SBOs). At the end of the workshop, after giving briefing on the important terms and definitions involved, in light of the PMBOK Guide, they were inquired to rate the perceived comparative significance of each PMKA for project success, as compared to other PMKAs, using 5-point likert scale, which was ranging from 1 (least important) to 5 (most important). Later, it was observed that thirty-one questionnaires were completely filled while in one questionnaire the respondent perhaps forgot to mark one item. After entering data in the MS Excel sheet, this missing value was filled using the neighbour generating method following Liu et al., 2017. Therefore, the data of thirty two respondents $\left(\mathrm{N}=\mathrm{N}_{\mathrm{SBO}}+\mathrm{N}_{\mathrm{PBO}}=\right.$ 32) were used for data analysis. Fourteen were from PBOs $\left(\mathrm{N}_{\mathrm{PBO}}=14\right)$ and eighteen were from $\mathrm{SBO}\left(\mathrm{N}_{\mathrm{SBO}}=18\right)$. Since the sample was small thus the data analysis through the Grey Theory was considered suitable because, unlike statistical methods, the grey models (e.g., GRA) reportedly work well with small data sets as well and without any concern for probability distribution (Javed \& Liu, 2019, 2017; Liu \& Lin, 2010; Yue, 2009). Microsoft Excel was used to calculate values for all four methods. In this paper, following Javed et al. (2015), the companies from the manufacturing industries are called Product-based Organizations (PBOs) and the companies from the service industries are called Service-based Organizations (SBOs).

\section{Results and discussion}

In the following sections the results achieved through Deng's GRA model and other three MCDM models have been presented. The correlation between GRA based ranking and other MCDM models' based rankings have also been presented to make the comparison convenient. 


\subsection{Results through GRA method}

The results obtained through the equally weighted Deng's Grey Relational Analysis (GRA) method are shown in Table 1 and 2. Here mean images are the geometric means of the original responses, normalized images are the values resulting from the normalization of the mean images within 0 and 1 and the difference images are the $\left|x_{0}(k)-x_{i}(k)\right|$ while considering $X_{0}=(1,1, \ldots, 1)$.

Table 1. Estimating Grey Relational Coefficients (GRCs)

\begin{tabular}{|l|c|c|c|c|c|c|c|c|}
\hline & \multicolumn{2}{|c}{ Mean Images } & \multicolumn{2}{c|}{ Normalized Images } & Difference Images & \multicolumn{2}{c|}{ GRC } \\
\hline & SBOs & PBOs & SBOs & PBOs & SBOs & PBOs & SBOs & PBOs \\
\hline PCmM & 4.3470 & 3.9681 & 0.8252 & 0.8127 & 0.1748 & 0.1873 & 0.7410 & 0.7275 \\
\hline PCoM & 4.5117 & 3.7829 & 1.0000 & 0.5427 & 0.0000 & 0.4573 & 1.0000 & 0.5223 \\
\hline PHRM & 3.8552 & 3.7655 & 0.3033 & 0.5173 & 0.6967 & 0.4827 & 0.4178 & 0.5088 \\
\hline PIM & 3.5694 & 3.9865 & 0.0000 & 0.8394 & 1.0000 & 0.1606 & 0.3333 & 0.7569 \\
\hline PPM & 3.7339 & 3.4105 & 0.1746 & 0.0000 & 0.8254 & 1.0000 & 0.3772 & 0.3333 \\
\hline PQM & 4.3470 & 4.0967 & 0.8252 & 1.0000 & 0.1748 & 0.0000 & 0.7410 & 1.0000 \\
\hline PRM & 3.5929 & 3.4974 & 0.0249 & 0.1266 & 0.9751 & 0.8734 & 0.3390 & 0.3641 \\
\hline PSHM & 3.7755 & 3.5269 & 0.2187 & 0.1697 & 0.7813 & 0.8303 & 0.3902 & 0.3759 \\
\hline PSM & 4.0276 & 3.9681 & 0.4862 & 0.8127 & 0.5138 & 0.1873 & 0.4932 & 0.7275 \\
\hline PTM & 4.0750 & 4.0505 & 0.5365 & 0.9327 & 0.4635 & 0.0673 & 0.5189 & 0.8814 \\
\hline
\end{tabular}

Table 2. Estimating Grey Relational Grades (GRGs) and Prioritization

\begin{tabular}{|l|c|c|c|c|c|c|}
\hline & $\begin{array}{c}w_{1} \cdot \text { GRC } \\
(\text { PBOs })\end{array}$ & Rank & $\begin{array}{c}w_{2} \cdot \text { GRC } \\
(\text { SBOs })\end{array}$ & Rank & $\begin{array}{c}\text { Equally Weighted } \text { GRG }^{*} \\
\text { (Overall) }\end{array}$ & Rank \\
\hline PCmM & 0.36374 & $4 / 5$ & 0.37048 & 2 & 0.73422 & 3 \\
\hline PCoM & 0.26115 & 6 & 0.5 & 1 & 0.76115 & 2 \\
\hline PHRM & 0.25441 & 7 & 0.2089 & 6 & 0.46331 & 7 \\
\hline PIM & 0.37845 & 3 & 0.16667 & 10 & 0.54512 & 6 \\
\hline PPM & 0.16667 & 10 & 0.18862 & 8 & 0.35528 & 9 \\
\hline PQM & 0.50000 & 1 & 0.37048 & 2 & 0.87048 & 1 \\
\hline PRM & 0.18203 & 9 & 0.16948 & 9 & 0.35151 & 10 \\
\hline PSHM & 0.18793 & 8 & 0.19512 & 7 & 0.38304 & 8 \\
\hline PSM & 0.36374 & $4 / 5$ & 0.24659 & 5 & 0.61033 & 5 \\
\hline PTM & 0.44072 & 2 & 0.25947 & 4 & 0.7002 & 4 \\
\hline
\end{tabular}

Notes: ${ }^{\star}$ Equally weighted: $w_{1}=w_{2}=0.5$ at $\xi=0.5$.

\subsection{Results through AHP, SAW and BWM methods}

The results obtained through the Analytic Hierarchy Process (AHP), Simple Additive Weighting (SAW) and Best Worst Method (BWM) approaches are shown in the Tables 3, 4 and 5, respectively. 
Table 3. Analytic Hierarchy Process

\begin{tabular}{|l|c|c|c|c|c|c|}
\hline \multicolumn{1}{|c|}{ AHP } & $\begin{array}{c}\text { Weights } \\
\text { (PBOs) }\end{array}$ & Rank & $\begin{array}{c}\text { Weights } \\
\text { (SBOs) }\end{array}$ & Rank & $\begin{array}{c}\text { Weights } \\
\text { (Overall) }\end{array}$ & Rank \\
\hline PCmM & 0.104279 & $4 / 5$ & 0.109124 & 2 & 0.107043 & $2 / 3$ \\
\hline PCoM & 0.09941 & 6 & 0.113259 & 1 & 0.107043 & $2 / 3$ \\
\hline PHRM & 0.098953 & 7 & 0.096779 & 6 & 0.097784 & 6 \\
\hline PIM & 0.104761 & 3 & 0.089605 & 10 & 0.096004 & 7 \\
\hline PPM & 0.089624 & 10 & 0.093734 & 8 & 0.09197 & 9 \\
\hline PQM & 0.10766 & 1 & 0.10912 & 2 & 0.10855 & 1 \\
\hline PRM & 0.091908 & 9 & 0.090193 & 9 & 0.090995 & 10 \\
\hline PSHM & 0.092684 & 8 & 0.094779 & 7 & 0.093914 & 8 \\
\hline PSM & 0.104279 & $4 / 5$ & 0.101105 & 5 & 0.102545 & 5 \\
\hline PTM & 0.106444 & 2 & 0.102296 & 4 & 0.104154 & 4 \\
\hline
\end{tabular}

Table 4. Simple Additive Weighting

\begin{tabular}{|l|c|c|c|c|c|c|}
\hline \multicolumn{1}{|c|}{ SAW } & $\begin{array}{c}\text { Weights } \\
\text { (PBOs) }\end{array}$ & Rank & $\begin{array}{c}\text { Weights } \\
\text { (SBOs) }\end{array}$ & Rank & $\begin{array}{c}\text { Weights } \\
\text { (Overall) }\end{array}$ & Rank \\
\hline PCmM & 0.104279 & $4 / 5$ & 0.109125 & 2 & 0.107043 & $2 / 3$ \\
\hline PCoM & 0.09941 & 6 & 0.113259 & 1 & 0.107043 & $2 / 3$ \\
\hline PHRM & 0.098953 & 7 & 0.096779 & 6 & 0.097784 & 6 \\
\hline PIM & 0.104761 & 3 & 0.089605 & 10 & 0.096004 & 7 \\
\hline PPM & 0.089624 & 10 & 0.093734 & 8 & 0.09197 & 9 \\
\hline PQM & 0.107657 & 1 & 0.109125 & 2 & 0.108547 & 1 \\
\hline PRM & 0.091908 & 9 & 0.090193 & 9 & 0.090995 & 10 \\
\hline PSHM & 0.092684 & 8 & 0.094779 & 7 & 0.093914 & 8 \\
\hline PSM & 0.104279 & $4 / 5$ & 0.101105 & 5 & 0.102545 & 5 \\
\hline PTM & 0.106444 & 2 & 0.102296 & 4 & 0.104154 & 4 \\
\hline
\end{tabular}

Table 5. Best Worst Method

\begin{tabular}{|l|c|c|c|c|c|c|}
\hline \multicolumn{1}{|c|}{ BWM } & $\begin{array}{c}\text { Weights } \\
(\text { PBOs) }\end{array}$ & Rank & $\begin{array}{c}\text { Weights } \\
\text { (SBOs) }\end{array}$ & Rank & $\begin{array}{c}\text { Weights } \\
\text { (Overall) }\end{array}$ & Rank \\
\hline PCmM & 0.102467 & $4 / 5$ & 0.107037 & 2 & 0.105013 & $2 / 3$ \\
\hline PCoM & 0.097683 & 6 & 0.111093 & 1 & 0.105013 & $2 / 3$ \\
\hline PHRM & 0.097234 & 7 & 0.094928 & 6 & 0.09593 & 6 \\
\hline PIM & 0.102941 & 3 & 0.087891 & 10 & 0.094184 & 7 \\
\hline PPM & 0.088067 & 10 & 0.091942 & 8 & 0.090226 & 9 \\
\hline PQM & 0.105786 & 1 & 0.107037 & 2 & 0.106488 & 1 \\
\hline PRM & 0.090311 & 9 & 0.088468 & 9 & 0.08927 & 10 \\
\hline PSHM & 0.091074 & 8 & 0.092966 & 7 & 0.092133 & 8 \\
\hline PSM & 0.102467 & $4 / 5$ & 0.099172 & 5 & 0.1006 & 5 \\
\hline PTM & 0.104595 & 2 & 0.100339 & 4 & 0.102179 & 4 \\
\hline
\end{tabular}




\subsection{Comparative analysis}

The rankings produced through AHP, SAW and BWM, are exactly same with each method unable to distinguish PCmM and PCoM based on their relative importance. Thus it is difficult to distinguish which one is $2^{\text {nd }}$ and $3^{\text {rd }}$ important knowledge area. (1) However, only GRA model distinguished them and gave PCoM and PCmM second and third ranks respectively. Thus, it is clearly evident that the GRA model, which is better armed to handle uncertainty, clearly outperformed other three MCDM methods and its output is more helpful for decision making. (2) Also, the positions of PHRM and PIM have been interchanged in grey relational analysis. These two points differentiated the ranking obtained through GRA with that of other three MCDM methods. This difference is because of the fact that among the four MCDM methods only the GRA model is guided by a theory that incorporates uncertainty. Is it possible that a theory that can perform well under uncertainty can perform well as well when uncertainty is minimum? Fortunately, as far as GRA model is concerned just by tailoring its one parameter, the distinguishing coefficient, one can make it work like other MCDM methods. To do so, the authors changed the value of the distinguishing coefficient $(\xi)$ and obtained the optimum value of the distinguishing coefficient (i.e., $0.86887559934486=\xi_{\mathrm{o}}$ ) at which the ranking of GRA was most comparable to the other three methods. This value can easily be obtained from any linear programming approach by iterating $\xi$ from 0 to 1 until the ranks obtained through GRA are comparable to that of other methods. At this value, both PCmM and PCoM had equal ranks, as shown in Table 6. Here it should be noted that even though the distinguishing coefficient does not influence the relative order of the grey relational coefficients however it does influence grey relational grades and their relative order (Song \& Shepperd, 2011). This can be confirmed from Figures 1 and 2 as well.

Table 6. Comparative analysis

\begin{tabular}{|c|c|c|c|c|c|c|c|c|c|c|c|c|}
\hline & \multicolumn{3}{|c|}{ BWM } & \multicolumn{3}{|c|}{ AHP } & \multicolumn{3}{|c|}{ SAW } & \multicolumn{3}{|c|}{$\operatorname{GRA}\left(\xi=\xi_{\mathrm{o}}\right)$} \\
\hline & $\stackrel{\infty}{0}$ & $\begin{array}{l}0 \\
\infty \\
\infty\end{array}$ & F & $\begin{array}{l}00 \\
0 \\
\tilde{n}\end{array}$ & $\begin{array}{l}0 \\
\infty \\
\infty\end{array}$ & $\begin{array}{l}\overline{\overline{3}} \\
\text { 岕 } \\
0\end{array}$ & $\begin{array}{l}\infty \\
0 \\
0\end{array}$ & 点 & 苞 & 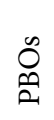 & Oి & 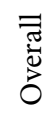 \\
\hline $\mathrm{PCmM}$ & $4 / 5$ & $2 / 3$ & $2 / 3$ & $4 / 5$ & $2 / 3$ & $2 / 3$ & $4 / 5$ & $2 / 3$ & $2 / 3$ & $4 / 5$ & $2 / 3$ & $2 / 3$ \\
\hline PCoM & 6 & 1 & $2 / 3$ & 6 & 1 & $2 / 3$ & 6 & 1 & $2 / 3$ & 6 & 1 & $2 / 3$ \\
\hline PHRM & 7 & 6 & 6 & 7 & 6 & 6 & 7 & 6 & 6 & 7 & 6 & 7 \\
\hline PIM & 3 & 10 & 7 & 3 & 10 & 7 & 3 & 10 & 7 & 3 & 10 & 6 \\
\hline PPM & 10 & 8 & 9 & 10 & 8 & 9 & 10 & 8 & 9 & 10 & 8 & 9 \\
\hline PQM & 1 & $2 / 3$ & 1 & 1 & $2 / 3$ & 1 & 1 & $2 / 3$ & 1 & 1 & $2 / 3$ & 1 \\
\hline PRM & 9 & 9 & 10 & 9 & 9 & 10 & 9 & 9 & 10 & 9 & 9 & 10 \\
\hline PSHM & 8 & 7 & 8 & 8 & 7 & 8 & 8 & 7 & 8 & 8 & 7 & 8 \\
\hline PSM & $4 / 5$ & 5 & 5 & $4 / 5$ & 5 & 5 & $4 / 5$ & 5 & 5 & $4 / 5$ & 5 & 5 \\
\hline PTM & 2 & 4 & 4 & 2 & 4 & 4 & 2 & 4 & 4 & 2 & 4 & 4 \\
\hline
\end{tabular}




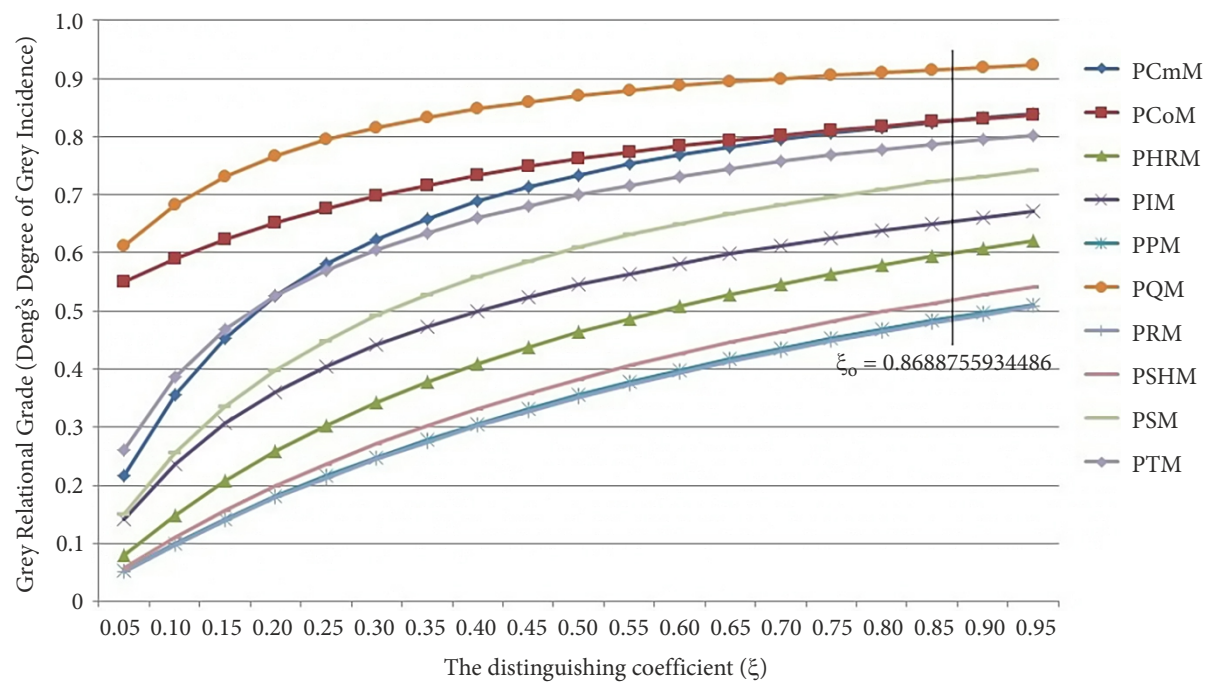

Figure 1. The variation in Grey Relational Grade with respect to $\xi$

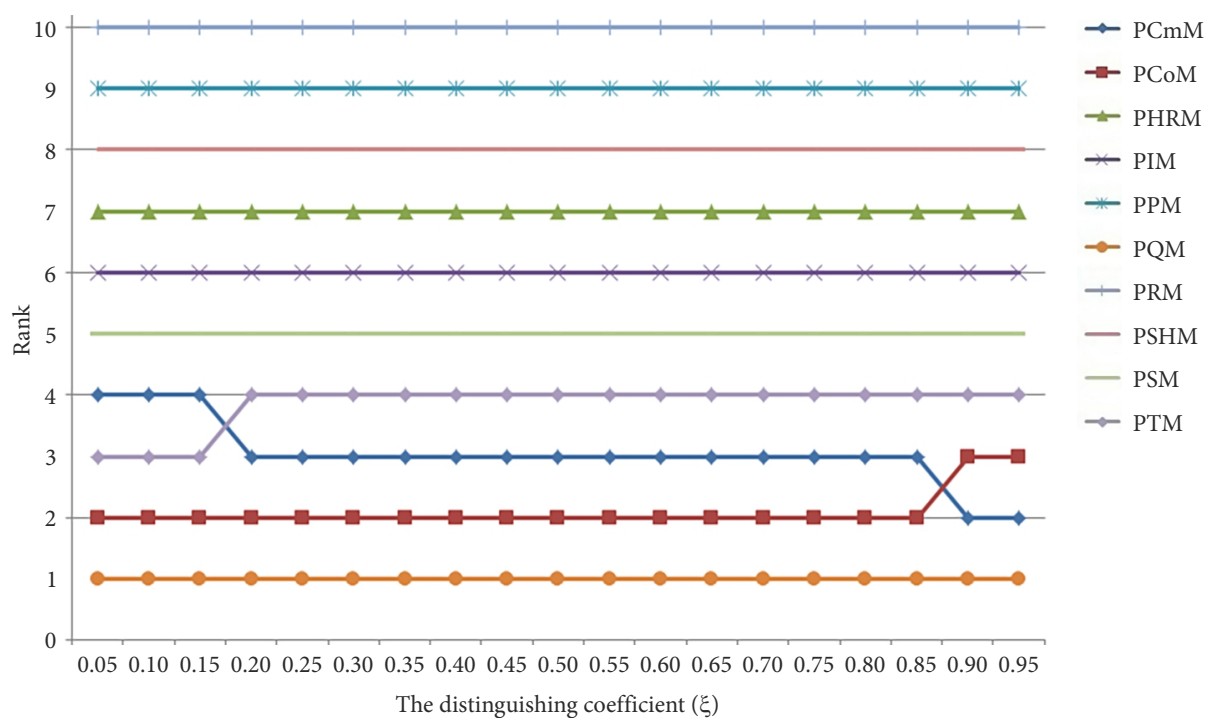

Figure 2. The variation in Ranking with variation in $\xi$

As can be seen from Table 6, using all four methods, for Product-based Organizations (PBOs), the following ranking (as per weights) was obtained

$$
\mathrm{PQM}>\mathrm{PTM}>\mathrm{PIM}>\mathrm{PCmM}=\mathrm{PSM}>\mathrm{PCOM}>\mathrm{PHRM}>\mathrm{PSHM}>\mathrm{PRM}>\mathrm{PPM} .
$$

The results reveal that for the project management professionals from manufacturing sector, Project Quality, Time and Integration Management are the most important knowledge areas whereas Project Risk and Procurement Management are viewed as least important areas. 
As can be seen from Table 6, using all four methods, for Service-based Organizations (SBOs), the following ranking (as per weights) was obtained

$$
\mathrm{PCOM}>\mathrm{PCmM}=\mathrm{PQM}>\mathrm{PTM}>\mathrm{PSM}>\mathrm{PHRM}>\mathrm{PSHM}>\mathrm{PPM}>\mathrm{PRM}>\mathrm{PIM} .
$$

The results reveal that for the project management professionals from service sector, Project Cost, Quality and Communication, and Time Management are the most important knowledge areas whereas Project Risk and Integration Management are viewed as least important knowledge areas.

However, in overall ranking this is one variation. Overall, the following ranking was obtained, using GRA model (at $\xi_{\mathrm{o}}$ ).

$$
\mathrm{PQM}>\mathrm{PCmM}=\mathrm{PCoM}>\mathrm{PTM}>\mathrm{PSM}>\mathrm{PIM}>\mathrm{PHRM}>\mathrm{PSHM}>\mathrm{PPM}>\mathrm{PRM} \text {. }
$$

The results reveal that generally Project Quality, Communication and Cost, and Time Management are likely the four top most significant PMKAs for the Pakistani project management professionals who are more likely to overlook Project Risk and Integration Management.

Overall, the following ranking was obtained, using other three models.

$$
\mathrm{PQM}>\mathrm{PCmM}=\mathrm{PCoM}>\mathrm{PTM}>\mathrm{PSM}>\mathrm{PHRM}>\mathrm{PIM}>\mathrm{PSHM}>\mathrm{PPM}>\mathrm{PRM} .
$$

The only difference is the interchange in the position of Project Integration and Project Human Resources Management related knowledge areas.

Here it is worth mentioning that for all values between 0 and 1 only at $\xi_{0}=$ 0.86887559934486 , the ranks obtained through GRA model were most comparable to that of ranks obtained through other MCDM methods. Thus, at $\xi=\xi_{0}$, GRA model is most likely to behave like any other MCDM method however otherwise its ranks are likely to be different, and more acceptable to the decision-makers who consider uncertainty in the decision making. Based on the GRA model based results, the current study proposes a set of two ranks, as shown in the Table 7, and it is up to the decision-maker which ranks they choose to trust. However, in the traditional MCDM methods, all evaluation measures are precise, which is bit ideal if one weighs in the mind the real life uncertainties that are usual (Liao \& Xu, 2013). Thus, considering uncertainty is better approach than foregoing it in real world problems thus the ranking obtained through the GRA model (at $\xi=0.5$ ) is more representative of actual situation. Here it should be noted that $\xi_{\mathrm{o}}=0.86887559934486$ can be calculated by varying the value of $\xi$ from 0 to 1 and recording the turning points. The turning point where GRA based ranking is most acceptable (e.g., the most comparable to that of other MCDM methods) is the point where $\xi_{\mathrm{o}}$ lies. Here it should be noted that purpose of predicting $\xi_{\mathrm{o}}$ is not to propose another GRA model to compete with already influential Deng's GRA model but to enrich our understanding of the behavior of GRA model and its sensitivity to $\xi$.

In order to confirm that at $\xi=\xi_{\mathrm{o}}$ (and succeeding values) the ranking of GRA model is most comparable to the rankings obtained through other three MCDM methods, the authors decided to estimate the correlational measure. For this purpose, Absolute GRA model (Javed \& Liu, 2019) was used to calculate Absolute GRG, or absolute degree of grey relation, between the two ranking orders (one by GRA model; other by other three MCDM methods). Absolute GRA model can serve as a suitable grey systems approach to determine the 
correlation between two data sequences bases on their closeness (integral proximity). The grey correlation measures thus obtained against the $\xi$ (at $0.1,0.2,0.3,0.4,0.5,0.6,0.7,0.8$ and 0.9 ) are illustrated in the Figure 3. One can see that at $\xi=\xi_{\mathrm{o}}$ (and succeeding values) the ranking order obtained through Deng's GRA model was most comparable to the ranking orders obtained through the other methods. This is very interesting and novel insight of Deng's GRA model.

Table 7. The variation in GRA based ranks for $\xi=\left(0.5, \xi_{0}\right)$

\begin{tabular}{|l|c|c|c|c|c|c|}
\hline & \multicolumn{3}{|c|}{ GRA $(\xi=0.5)$} & \multicolumn{3}{c|}{ GRA $\left(\xi=\xi_{\mathrm{o}}\right)$} \\
\hline & $\begin{array}{c}\text { Rank } \\
(\text { PBOs })\end{array}$ & $\begin{array}{c}\text { Rank } \\
(\text { SBOs })\end{array}$ & $\begin{array}{c}\text { Rank } \\
(\text { Overall })\end{array}$ & $\begin{array}{c}\text { Rank } \\
(\text { PBOs })\end{array}$ & $\begin{array}{c}\text { Rank } \\
(\text { SBOs })\end{array}$ & $\begin{array}{c}\text { Rank } \\
(\text { Overall })\end{array}$ \\
\hline PCmM & $4 / 5$ & 2 & 3 & $4 / 5$ & $2 / 3$ & $2 / 3$ \\
\hline PCoM & 6 & 1 & 2 & 6 & 1 & $2 / 3$ \\
\hline PHRM & 7 & 6 & 7 & 7 & 6 & 7 \\
\hline PIM & 3 & 10 & 6 & 3 & 10 & 6 \\
\hline PPM & 10 & 8 & 9 & 10 & 8 & 9 \\
\hline PQM & 1 & 2 & 1 & 1 & $2 / 3$ & 1 \\
\hline PRM & 9 & 9 & 10 & 9 & 9 & 10 \\
\hline PSHM & 8 & 7 & 8 & 8 & 7 & 8 \\
\hline PSM & $4 / 5$ & 5 & 5 & $4 / 5$ & 5 & 5 \\
\hline PTM & 2 & 4 & 4 & 2 & 4 & 4 \\
\hline
\end{tabular}

Notes: $\xi_{\mathrm{o}}=0.86887559934486$.

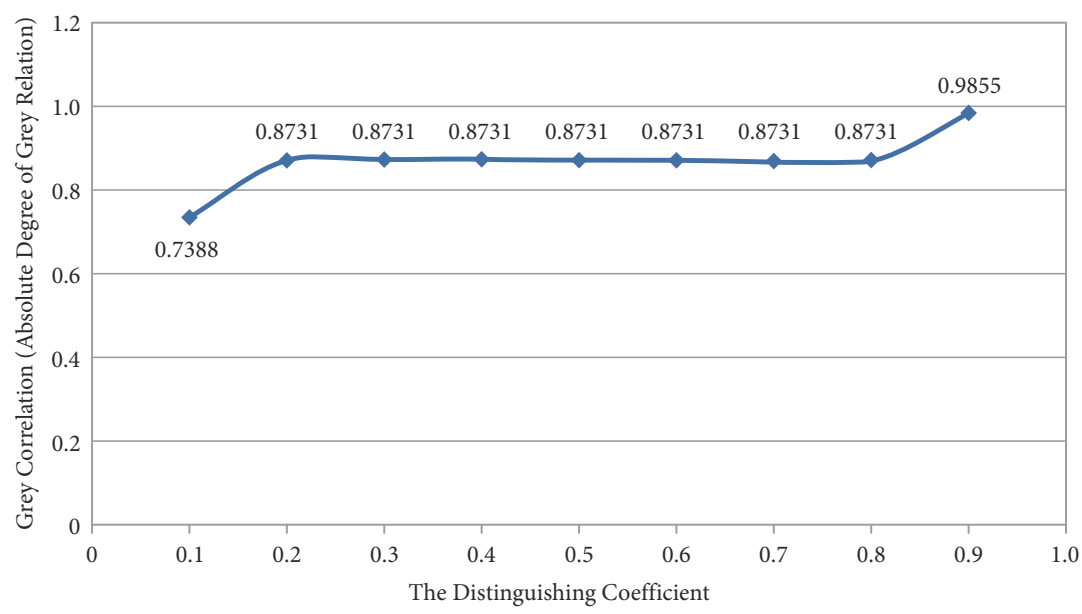

Figure 3. The variation in Grey Correlation with change in $\xi$ 


\section{Conclusion and recommendations}

Decision making is common activity of humans that involves taking effective approach to rank the alternatives followed by the selection of the best alternative (Yang et al., 2017). In real-world problems, especially the problems people face in organizations or projects, complexities and uncertainties are likely to arise and cannot always be predicted beforehand (Wu et al., 2018). Complexities and uncertainties are key attributes associated with projects and their management/organizing. In fact, these factors distinguish a project from what is not a project. Grey system theory has seen wide number of applications in various areas including project management and its flagship model, Deng's GRA model, is gaining exceeding importance in management sciences for multiple-attribute decision making and optimizations. However, its one parameter, the Distinguishing Coefficient $(\xi)$, received very less attention in literature and its influence on the final ranking of the alternatives remained debatable. In the current study GRA model has been applied on various values of $\xi$ and some interesting insights have been drawn, when the results were compared with that of SAW, AHP and BWM.

The results from all methods reveal that in manufacturing industry, project knowledge areas related to quality, time and integration are perceived to be the most important while that of risk and procurement are relatively least important. In service industry, knowledge areas related to cost, communication, quality and time are perceived to be the most important while that of risk and integration are relatively least important. However, overall, knowledge areas related to quality, communication, cost and time are most important while that of procurement and risk are relatively least important. Only the position of project integration and human resources management related knowledge areas interchanged their position in GRA and other methods. However, the supposedly underrating of project risk management was a striking finding. The study suggests that by overlooking the significance of project risk management, the Pakistani project management professionals are more likely to make the projects more vulnerable to unforeseen circumstances. One can also argue that the reason for their overlooking project risk management can be attributed to their allegedly higher confidence level in the effectiveness of their project management strategies. Nevertheless, still this cannot nullify the significance of project risk management in a world where un-predictabilities and uncertainties are increasing with time. One can also argue that the results doesn't imply risk management is not important, in fact it merely gives relative importance of risk management with respect to other knowledge areas in light of the respondents' observations. Further, the dependence of the ten knowledge areas on each other is very probable thus importance of one knowledge area doesn't completely negate the importance of the other.

Since the underline purpose of any MCDM method is to assist the decision-maker in making rational decisions (Mi et al., 2019) therefore it is difficult to establish the rationality of decision if the decision-making methodology did not incorporate uncertainty, which is the usual phenomenon in most real-world problems. Why a problem should be called "problem" if there isn't any uncertainty? Most importantly, the study suggests GRA model is a better alternative to other comparable MCDM methods as its methodology inherently incorporates 
uncertainty in data and by varying the value of the distinguishing coefficient $(\xi)$ it enables the decision-makers to analyze the sensitivity of the final outcome (ranking). Further, if one intends to see what would be the ranking of different decision alternatives when uncertainty is minimum, which is though very unlikely in real life cases, it allows the prediction of a value of distinguishing coefficient $\left(\xi_{\mathrm{o}}\right)$ where the GRA model almost works like any other MCDM method, which does not incorporates uncertainty. However, the current study seconds Kuo et al. (2008) and suggests that variation in $\xi$ allows a decision maker to analyze the sensitivity of the final results of GRA model, therefore, the future scholars, who intent to deploy GRA model, should perform the sensitivity analysis as well at different values of $\xi$ rather than merely reporting results at $\xi=0.5$.

The study seconds Kuo et al. (2008) and Song and Shepperd (2011), and argues that $\xi$ do influences the final order of decision alternatives, even though the influence is not significant. It is advised that when the decision environment surrounds uncertainty and different MCDM methods yield different "optimum" alternatives then one should resort to the alternative acceptable to the decision makers from the optimum alternatives produced by different but comparable methods. When methods are not comparable (because of robustness) then the optimum alternative provided by the more robust method should be acceptable. In the current study, AHP and BWM methods are relatively more robust than SAW method nevertheless they all were producing comparable results, which imply the problem was not complicated. Their rankings were same and each one of them could not distinguish between the second and third most important knowledge area. However, when GRA model (at $\xi=$ 0.5 ) is applied the resulting ranking order was slightly different, even though top 5 alternatives were still comparable, and it successfully distinguished second and third knowledge areas. This also signifies the robustness of GRA among all other methods. However, since much of the ranking was comparable a decision maker may think there was no need for sensitivity analysis however in principle executing the $\xi$ - driven sensitivity analysis is an acceptable setup as it can boost the confidence in the ranking order obtained through the GRA model. If the ranking order is stable for much of the variation in $\xi$ this implies the ranking order's stability and thus reliability. Another benefit, or insight, that one can draw from the $\xi$-driven sensitivity analysis is that it lets the decision makers to see at which points the ranking order obtained through GRA model is most comparable to that of other methods. For instance, in the current study, at $\xi=\xi_{\mathrm{o}}$ (and succeeding points), the correlation between the four ranking orders was maximum that demonstrated that at this point GRA model is going to treat the problem as a simple problem, rather than an uncertain problem, like other MCDM method in the current study. This is very novel and interesting insight and requires further explorations.

\section{Acknowledgements}

This study was supported by the National Natural Science Foundation of China (NSFC71771052 and 71372199). An older version of this paper (Javed \& Liu, 2017) was presented by S.A.J. at the 6th IEEE International Conference on Grey Systems and Intelligent Services, held in Stockholm, Sweden, from 8th to 11th August, 2017. 


\section{Funding}

This work was supported by the National Natural Science Foundation of China under Grant [NSFC-71771052 and 71372199 ].

\section{Author contributions}

All authors have equally contributed in the manuscript designing, writing, editing and preparation. Thus, all authors are co-first authors of the study. The names are written in alphabetical order.

\section{Disclosure statement}

The authors declare that they have no conflict of interest in this article.

\section{References}

Abhang, L. B., \& Hameedullah, M. (2012). Determination of optimum parameters for multi-performance characteristics in turning by using grey relational analysis. International Journal of Advanced Manufacturing Technology, 63(1-4), 13-24. https://doi.org/10.1007/s00170-011-3857-6

Afshari, A., Mojahed, M., \& Yusuff, R. (2010). Simple additive weighting approach to personnel selection problem. International Journal of Innovation, Management and Technology, 1(5), 511-515.

Ahmed, S., Vedagiri, P., \& Krishna Rao, K. V. (2017). Prioritization of pavement maintenance sections using objective based Analytic Hierarchy Process. International Journal of Pavement Research and Technology, 10(2), 158-170. https://doi.org/10.1016/j.ijprt.2017.01.001

Ahn, B. S. (2017). The analytic hierarchy process with interval preference statements. Omega, 67, 177-185 (United Kingdom). https://doi.org/10.1016/j.omega.2016.05.004

Bakker, R. M. (2010). Taking stock of temporary organizational forms: A systematic review and research agenda. International Journal of Management Reviews, 12(4), 466-486. https://doi.org/10.1111/j.1468-2370.2010.00281.x

Bourgault, M., Drouin, N., \& Hamel, E. (2008). Decision making within distributed project teams: An exploration of formalization and autonomy as determinants of success. Project Management Journal, 39(1 suppl), S97-S110. https://doi.org/10.1002/pmj.20063

Chou, S. Y., Chang, Y. H., \& Shen, C. Y. (2008). A fuzzy simple additive weighting system under group decision-making for facility location selection with objective/subjective attributes. European Journal of Operational Research, 189(1), 132-145. https://doi.org/10.1016/j.ejor.2007.05.006

Crawford, L., \& Pollack, J. (2007). How generic are project management knowledge and practice? Project Management Journal, 38(1), 87-96. https://doi.org/10.1177/875697280703800109

Deng, J. (1989). Introduction to Grey System Theory. The Journal of Grey System, 1(1), 1-24.

Drouin, N., Müller, R., \& Sankaran, S. (2016). Novel approaches to organizational project management research: Translational and transformational. Project Management Journal, 47(1), e2-e2. https://doi.org/10.1002/pmj.21567

Dumrak, J., Baroudi, B., \& Hadjinicolaou, N. (2017). Exploring the Association between Project Management Knowledge Areas and Sustainable Outcomes. Procedia Engineering, 182, 157-164.

https://doi.org/10.1016/j.proeng.2017.03.152 
Eastham, J., Tucker, D. J., Varma, S., \& Sutton, S. M. (2014). PLM software selection model for project management using hierarchical decision modeling with criteria from $\mathrm{PMBOK}^{\circ}$ knowledge areas. Engineering Management Journal, 26(3), 13-24. https://doi.org/10.1080/10429247.2014.11432016

Floricel, S., Michela, J. L., \& Piperca, S. (2016). Complexity, uncertainty-reduction strategies, and project performance. International Journal of Project Management, 34(7), 1360-1383. https://doi.org/10.1016/j.ijproman.2015.11.007

Garel, G. (2013). A history of project management models: From pre-models to the standard models. International Journal of Project Management, 31(5), 663-669. https://doi.org/10.1016/j.ijproman.2012.12.011

Haeri, S. A. S., \& Rezaei, J. (2019). A grey-based green supplier selection model for uncertain environments. Journal of Cleaner Production, 221, 768-784. https://doi.org/10.1016/j.jclepro.2019.02.193

He, Q., Luo, L., Hu, Y., \& Chan, A. P. C. (2015). Measuring the complexity of mega construction projects in China - A fuzzy analytic network process analysis. International Journal of Project Management, 33(3), 549-563. https://doi.org/10.1016/j.ijproman.2014.07.009

Hietajärvi, A. M., \& Aaltonen, K. (2018). The formation of a collaborative project identity in an infrastructure alliance project. Construction Management and Economics, 36(1), 1-21. https://doi.org/10.1080/01446193.2017.1315149

Hwang, B. G., \& Ng, W. J. (2013). Project management knowledge and skills for green construction: Overcoming challenges. International Journal of Project Management, 31(2), 272-284. https://doi.org/10.1016/j.ijproman.2012.05.004

Javed, S., Javed, S., \& Sajid, A. S. (2015). Assessing the managerial perception of relative significance of ten Knowledge Areas on project success - A case from Pakistan. Journal of Management and Science, 5(3), 1-18.

Javed, S. A. (2019). A novel research on Grey Incidence Analysis models and its application in Project Management (Doctoral dissertation). Nanjing University of Aeronautics and Astronautics, Nanjing, P. R. China.

Javed, S. A., \& Liu, S. (2017). Evaluation of project management knowledge areas using grey incidence model and AHP. In 2017 International Conference on Grey Systems and Intelligent Services (GSIS) (pp. 120-120). IEEE. Stockholm, Sweden. https://doi.org/10.1109/GSIS.2017.8077684

Javed, S. A., \& Liu, S. (2019). Bidirectional Absolute GRA/GIA model for Uncertain Systems: Application in Project Management. IEEE Access, 7, 60885-60896. https://doi.org/10.1109/ACCESS.2019.2904632

Javed, S. A., Khan, A. M., Dong, W., Raza, A., \& Liu, S. (2019c). Systems evaluation through new Grey Relational Analysis approach: An application on thermal conductivity - Petrophysical parameters' relationships. Processes, 7(6), 348. https://doi.org/10.3390/pr7060348

Javed, S. A., Mahmoudi, A., Khan, A. M., Javed, S., \& Liu, S. (2018a). A critical review: Shape optimization of welded plate heat exchangers based on grey correlation theory. Applied Thermal Engineering, 144, 593-599. https://doi.org/10.1016/j.applthermaleng.2018.08.086

Javed, S. A., Syed, A. M., \& Javed, S. (2018b). Perceived organizational performance and trust in project manager and top management in project-based organizations. Grey Systems: Theory and Application, 8(3), 230-245. https://doi.org/10.1108/GS-01-2018-0009

Jiang, B. C., Tasi, S. L., \& Wang, C. C. (2002). Machine vision-based gray relational theory applied to IC marking inspection. IEEE Transactions on Semiconductor Manufacturing, 15(4), 531-539. https://doi.org/10.1109/TSM.2002.804906

Kaganer, E., Carmel, E., Hirscheim, R., \& Olsen, T. (2013). Managing the human cloud. MIT Sloan Management Review, 54(2), 22-32. https://sloanreview.mit.edu/wp-content/uploads/2012/12/ 26e19f5086.pdf 
Kerzner, H. (2014). Project management best practices: Achieving global excellence ( $4^{\text {th }}$ ed.). John Wiley \& Sons. https://doi.org/10.1002/9781118835531

Kerzner, H. (2017). Project management: A systems approach to planning, scheduling, and controlling (12 ${ }^{\text {th }}$ ed.). John Wiley \& Sons. 848 p. https://www.wiley.com/en-us/Project+Management\%3A+ A+Systems+Approach+to+Planning $\% 2 \mathrm{C}+$ Scheduling $\% 2 \mathrm{C}+$ and + Controlling\%2C+12th+Edition -p-9781119165354

Khalil, N., Kamaruzzaman, S. N., \& Baharum, M. R. (2016). Ranking the indicators of building performance and the users' risk via Analytical Hierarchy Process (AHP): Case of Malaysia. Ecological Indicators, 71, 567-576. https://doi.org/10.1016/j.ecolind.2016.07.032

Kuo, Y., Yang, T., \& Huang, G.-W. (2008). The use of grey relational analysis in solving multiple attribute decision-making problems. Computers \& Industrial Engineering, 55(1), 80-93. https://doi.org/10.1016/j.cie.2007.12.002

Li, B. J., Hu, L. P., He, C. H., \& Li, Y. H. (2011). Dynamical analysis on influencing factors of grain production in Henan Province based on grey systems theory. In Proceedings of 2011 IEEE International Conference on Grey Systems and Intelligent Services, GSIS'11 - Joint with the $15^{\text {th }}$ WOSC International Congress on Cybernetics and Systems (pp. 106-110). Nanjing, China. https://doi.org/10.1109/GSIS.2011.6044017

Liang, D., Darko, A. P., \& Xu, Z. (2019). Pythagorean fuzzy partitioned geometric Bonferroni mean and its application to multi-criteria group decision making with grey relational analysis. International Journal of Fuzzy Systems, 21, 115-128. https://doi.org/10.1007/s40815-018-0544-X

Liang, D., Kobina, A., \& Quan, W. (2018). Grey relational analysis method for probabilistic linguistic multi-criteria group decision-making based on geometric Bonferroni mean. International Journal of Fuzzy Systems, 20, 2234-2244. https://doi.org/10.1007/s40815-017-0374-2

Liao, H. C., Yang, L. Y., \& Xu, Z. S. (2018). Two new approaches based on ELECTRE II to solve the multiple criteria decision making problems with hesitant fuzzy linguistic term sets. Applied Soft Computing Journal, 63, 223-234. https://doi.org/10.1016/j.asoc.2017.11.049

Liao, H., \& Xu, Z. (2013). A VIKOR-based method for hesitant fuzzy multi-criteria decision making. Fuzzy Optimization and Decision Making, 12, 373-392. https://doi.org/10.1007/s10700-013-9162-0

Liao, H., \& Xu, Z. (2017). Hesitant fuzzy decision making methodologies and applications. Springer Singapore. https://doi.org/10.1007/978-981-10-3265-3

Liao, H., Jiang, L., Xu, Z., Xu, J., \& Herrera, F. (2017). A linear programming method for multiple criteria decision making with probabilistic linguistic information. Information Sciences, 415-416, 341-355. https://doi.org/10.1016/j.ins.2017.06.035

Liao, H., Xu, Z., \& Zeng, X. J. (2015). Novel correlation coefficients between hesitant fuzzy sets and their application in decision making. Knowledge-Based Systems, 82, 115-127. https://doi.org/10.1016/j.knosys.2015.02.020

Liu, S., \& Lin, Y. (2010). Grey systems: Theory and applications. Springer Berlin Heidelberg. https://doi.org/10.1007/978-3-642-16158-2

Liu, S., Yang, Y., \& Forrest, J. (2017). Grey data analysis: Methods, models and applications. Singapore: Springer Singapore. https://doi.org/10.1007/978-981-10-1841-1

MacCrimmon, K. R. (1968). Decisionmaking among multiple-attribute alternatives: A Survey and consolidated approach. Arpa Order.

Mahmoudi, A., \& Feylizadeh, M. R. (2018). A grey mathematical model for crashing of projects by considering time, cost, quality, risk and law of diminishing returns. Grey Systems: Theory and Application, 8(3), 272-294. https://doi.org/10.1108/GS-12-2017-0042

Mahmoudi, A., Bagherpour, M., \& Javed, S. A. (2019b). Grey earned value management: Theory and applications. IEEE Transactions on Engineering Management, 1-19 (in press).

https://doi.org/10.1109/TEM.2019.2920904 
Mahmoudi, A., Liu, S. F., Javed, S. A., \& Abbasi, M. (2019a). A novel method of solving linear programming with grey parameters. Journal of Intelligent \& Fuzzy Systems, 36(1), 161-172. https://doi.org/10.3233/JIFS-181071

Mesquida, A.-L., \& Mas, A. (2014). A project management improvement program according to ISO/ IEC 29110 and PMBOK •. Journal of Software: Evolution and Process, 26(9), 846-854. https://doi.org/10.1002/smr.1665

Mi, X., \& Liao, H. (2019). An integrated approach to multiple criteria decision making based on the average solution and normalized weights of criteria deduced by the hesitant fuzzy best worst method. Computers \& Industrial Engineering, 133, 83-94. https://doi.org/10.1016/j.cie.2019.05.004

Mi, X., Tang, M., Liao, H., Shen, W., \& Lev, B. (2019). The state-of-the-art survey on integrations and applications of the best worst method in decision making: Why, what, what for and what's next? Omega, 87, 205-225. https://doi.org/10.1016/j.omega.2019.01.009

Nguyen, L. D., Chih, Y.-Y., \& García de Soto, B. (2016). Knowledge areas delivered in project management programs: Exploratory study. Journal of Management in Engineering, 33(1). https://doi.org/10.1061/(ASCE)ME.1943-5479.0000473

Oun, T. A., Blackburn, T. D., Olson, B. A., \& Blessner, P. (2016). An enterprise-wide knowledge management approach to project management. Engineering Management Journal, 28(3), 179-192. https://doi.org/10.1080/10429247.2016.1203715

Padalkar, M., \& Gopinath, S. (2016). Six decades of project management research: Thematic trends and future opportunities. International Journal of Project Management, 34(7), 1305-1321. https://doi.org/10.1016/j.ijproman.2016.06.006

Project Management Institute. (2013). A guide to the project management body of knowledge (PMBOK guide). https://doi.org/10.1002/pmj.21345

Project Management Institute. (2017). Project management body of knowledge: A guide to the project management body of knowledge. https://doi.org/10.1002/pmj.20125

Quartey-Papafio, T. K., Liu, S., \& Javed, S. (2019). Grey relational evaluation of impact and control of malaria in Sub-Saharan Africa. Grey Systems: Theory and Application, 9(4), 415-431. https://doi.org/10.1108/GS-06-2019-0020

Rezaei, J. (2015). Best-worst multi-criteria decision-making method. Omega, 53, 49-57. https://doi.org/10.1016/j.omega.2014.11.009

Rezaei, J. (2016). Best-worst multi-criteria decision-making method: Some properties and a linear model. Omega, 109(3), 1911-1938. https://doi.org/10.1016/j.omega.2015.12.001

Rocha, L., Tereso, A., \& Couto, J. P. (2015). Project management: evaluation of the problems in the Portuguese construction industry. In A. Rocha, A. Correia, S. Costanzo, \& L. Reis (Eds.), New contributions in information systems and technologies. Advances in intelligent systems and computing (Vol. 353, pp. 69-78). Springer, Cham. https://doi.org/10.1007/978-3-319-16486-1_7

Saaty, T. L. (1986). Axiomatic foundation of the analytic hierarchy process. Management Science, 32(7), 841-855. https://doi.org/10.1287/mnsc.32.7.841

Saaty, T. L. (2008). Decision making with the analytic hierarchy process. International Journal of Services Sciences, 1(1). https://doi.org/10.1504/IJSSCI.2008.017590

Salet, W., Bertolini, L., \& Giezen, M. (2013). Complexity and uncertainty: Problem or asset in decision making of mega infrastructure projects? International Journal of Urban and Regional Research, 37(6), 1984-2000. https://doi.org/10.1111/j.1468-2427.2012.01133.x

Salimi, N., \& Rezaei, J. (2018). Evaluating firms' R\&D performance using best worst method. Evaluation and Program Planning, 66, 147-155. https://doi.org/10.1016/j.evalprogplan.2017.10.002 
Sallehuddin, R., Shamsuddin, S. M. Hj., \& Hashim, S. Z. M. (2008). Application of grey relational analysis for multivariate time series. In $20088^{\text {th }}$ International Conference on Intelligent Systems Design and Applications. Kaohsiung, Taiwan. https://doi.org/10.1109/ISDA.2008.181

Samanlioglu, F., Taskaya, Y. E., Gulen, U. C., \& Cokcan, O. (2018). A fuzzy AHP-TOPSIS-based group decision-making approach to it personnel selection. International Journal of Fuzzy Systems, 20, 1576-1591. https://doi.org/10.1007/s40815-018-0474-7

Serra, C. E. M. (2017). Benefits realization management: Strategic value from portfolios, programs, and projects. Boca Raton: Taylor \& Francis Group. https://www.worldcat.org/title/benefits-realizationmanagement-strategic-value-from-portfolios-programs-and-projects/oclc/956583875

Shabbir, R., \& Ahmad, S. S. (2016). Water resource vulnerability assessment in Rawalpindi and Islamabad, Pakistan using Analytic Hierarchy Process (AHP). Journal of King Saud University - Science, 28(4), 293-299. https://doi.org/10.1016/j.jksus.2015.09.007

Shaverdi, M., Ramezani, I., Tahmasebi, R., \& Rostamy, A. A. A. (2016). Combining fuzzy AHP and fuzzy TOPSIS with financial ratios to design a novel performance evaluation model. International Journal of Fuzzy Systems, 18(2), 248-262. https://doi.org/10.1007/s40815-016-0142-8

Song, Q., \& Shepperd, M. (2011). Predicting software project effort: A grey relational analysis based method. Expert Systems with Applications, 38(6), 7302-7316.

https://doi.org/10.1016/j.eswa.2010.12.005

Taha, H. A. (2014). Operations research - An introduction (Chapter 5, $9^{\text {th }}$ ed.). Pearson Education, Inc.

Vanhoucke, M. (2013). Project management with dynamic scheduling - Baseline scheduling, risk analysis and project control ( $2^{\text {nd }}$ ed.). Springer-Verlag, Berlin, Heidelberg.

https://doi.org/10.1007/978-3-642-40438-2_5

Winter, M., Smith, C., Morris, P., \& Cicmil, S. (2006). Directions for future research in project management: The main findings of a UK government-funded research network. International Journal of Project Management, 24(8), 638-649. https://doi.org/10.1016/j.ijproman.2006.08.009

Wu, H., Xu, Z., Ren, P., \& Liao, H. (2018). Hesitant fuzzy linguistic projection model to multi-criteria decision making for hospital decision support systems. Computers and Industrial Engineering, 115, 449-458. https://doi.org/10.1016/j.cie.2017.11.023

Wu, L. F., Liu, S. F., Yao, L. G., \& Yan, S. L. (2013). Grey convex relational degree and its application to evaluate regional economic sustainability. Scientia Iranica, 20(1), 44-49. https://doi.org/10.1016/j.scient.2012.11.002

Wu, W. Y., \& Chen, S. P. (2005). A prediction method using the grey model GMC $(1, n)$ combined with the grey relational analysis: A case study on Internet access population forecast. Applied Mathematics and Computation, 169(1), 198-217. https://doi.org/10.1016/j.amc.2004.10.087

$\mathrm{Xu}, \mathrm{Z}$., \& Liao, H. (2014). Intuitionistic fuzzy analytic hierarchy process. IEEE Transactions on Fuzzy Systems, 22(4), 749-761. https://doi.org/10.1109/TFUZZ.2013.2272585

Yang, X., Xu, Z., \& Liao, H. (2017). Correlation coefficients of hesitant multiplicative sets and their applications in decision making and clustering analysis. Applied Soft Computing Journal, 61, 935-946. https://doi.org/10.1016/j.asoc.2017.08.011

Yue, H. (2009). Grey absolute degree of incidence analysis of citation indicators of management academic journals. In $3^{\text {rd }}$ International Symposium on Intelligent Information Technology Application, IITA 2009 (pp. 19-22). Shanghai, China. IEEE. https://doi.org/10.1109/IITA.2009.258

Zahedi, F. (1986). The analytic hierarchy process - A survey of the method and its applications. INFORMS Journal on Applied Analytics, 16(4). https://doi.org/10.1287/inte.16.4.96

Zavadskas, E. K., Turskis, Z., \& Tamošaitienė, J. (2008). Multicriteria selection of project managers by applying grey criteria. Technological and Economic Development of Economy, 14(4), 462-477. https://doi.org/10.3846/1392-8619.2008.14.462-477 
Zavadskas, E. K., Vilutienė, T., Turskis, Z., \& Tamosaitienė, J. (2010). Contractor selection for construction works by applying saw-g and topsis grey techniques. Journal of Business Economics and Management, 11(1), 34-55. https://doi.org/10.3846/jbem.2010.03

Zhang, K., Ye, W., \& Zhao, L. (2012). The absolute degree of grey incidence for grey sequence base on standard grey interval number operation. Kybernetes, 41(7/8), 934-944. https://doi.org/10.1108/03684921211257784

Zwikael, O. (2009). The relative importance of the PMBOK ${ }^{\circ}$ guide's nine knowledge areas during project planning. Project Management Journal, 40(4), 94-103. https://doi.org/10.1002/pmj.20116 